\title{
Characterization of Complex Retained Austenite on a TRIP800 Automotive Steel
}

\author{
NI Makris ${ }^{1 *}, \mathrm{~S}$ Deligiannis ${ }^{1}$, A Alexandratou ${ }^{1}, \mathrm{P}_{\text {Tsakiridis }}{ }^{1}$ and G Fourlaris ${ }^{1}$
}

1. Lab. of Physical Metallurgy and Center for Electron Microscopy, School of Mining and Metallurgical Engineering, National Technical University of Athens, 15780 Athens, Greece.

*Corresponding author: nikolaos.i.makris@gmail.com

Automotive industry aims to reduce fuel consumption and greenhouse gas emissions by down-gauging car autobody (body-in-white) structures, while offering improved passive safety of vehicles, via enhanced crash-worthiness. Transformation-Induced Plasticity (TRIP) steels are Advanced multiphase High Strength Steels (AHSS), characterized by high energy impact absorption potential, owing to the combination of exceptional ductility, ultimate tensile strength, and work-hardening behavior and specifically designed for applications such as crumble safety zones of passenger vehicles [1].

TRIP steel mechanical properties are attributed to the coexistence of equiaxed recrystallized ferrite, bainitic ferrite and most importantly interlath (InterRA) and intralath (IntraRA) retained austenite [2]. The key factor to achieving stabilization of retained austenite in the final microstructure is by step partitioning of carbon through Intercritical Annealing (IA) and Isothermal Bainite Transformation (IBT). The purpose of this study is to investigate retained austenite stability, assess and quantify attained volume fractions and spatial distributions and a full characterization of obtained morphologies. It is envisaged that such information could be useful for specific alloy design and improved processing routes for TRIP steels.

A development cold-rolled annealed TRIP steel was employed for the present study, having a chemical composition $0.18 \mathrm{wt} \% \mathrm{C}, 1.33 \mathrm{wt} \% \mathrm{Mn}, 1.67 \% \mathrm{wt}$ Si. Carbon and Manganese are principally used as austenite stabilizers, while silicon prevents carbide precipitation [2]. IA took place at $775^{\circ} \mathrm{C}$ (targeting an $65 \% \alpha+35 \% \gamma$ volume fraction with $10 \mu \mathrm{m}$ average grain size), for $15 \mathrm{mins}$. IBT time and temperature are considered as variables and could take place at either $350^{\circ} \mathrm{C}$ or $400^{\circ} \mathrm{C}$ for $60,120,300$ and 1800 s on a molten metal bath and water quenched at ambient. Theoretical calculated TTT diagram and experimental IBT treatment are shown in Fig.1. Standardized metallographic preparation was employed for thin sample preparation, employing a Gatan 691PIPS unit. TEM analysis was carried out on a Jeol 2100HR unit.

This study highlighted the presence of interlath and intralath retained austenite formation, its metastability linked to different IBT time and temperature (Figs.2-5). Bainitic ferrite with high Si/Mn ratio (Fig.6) does not precipitate intralath cementite while RA dispersions appear to be stabilized. Carbon diffusion is governed by the $\mathrm{Si} / \mathrm{Mn}$ ratio and results in the mechanical stabilization of intralath retained austenite within bainitic ferrite. Theoretical calculations of phase transformations are in good agreement with the experimental results obtained.

The present study offers useful insight on the mechanisms of stabilization of RA and could offer valuable advice for improved alloy design and modified processing routes for TRIP 800 automotive steels [3].

\section{References:}

[1] BC De Cooman, Current Opinion in Solid State and Materials Science 8 (2004), p. 285.

[2] LC Chang and HKDH. Bhadeshia, Materials Science and Technology 11 (1995), p. 874. 
[3] NI Makris is grateful for financial support provided by the Eugenides Foundation, Athens, GR.

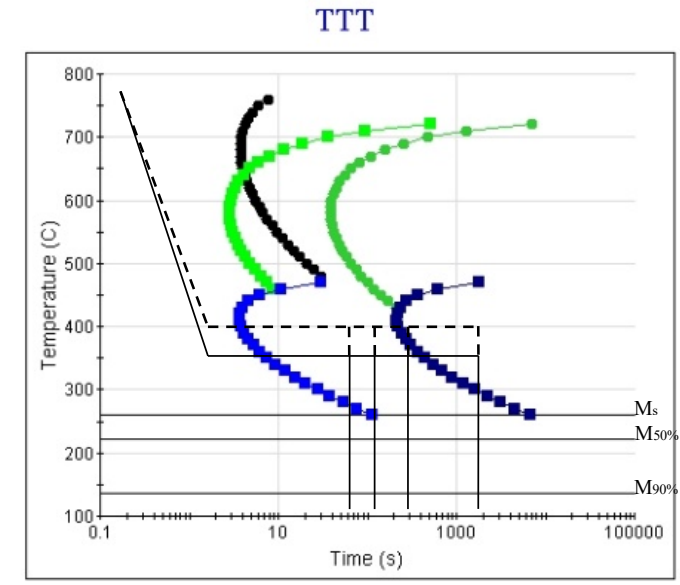

Figure 1. Theoretical calculated TTT (Time Temperature Transformation) diagram and experimental IBT treatments paths.

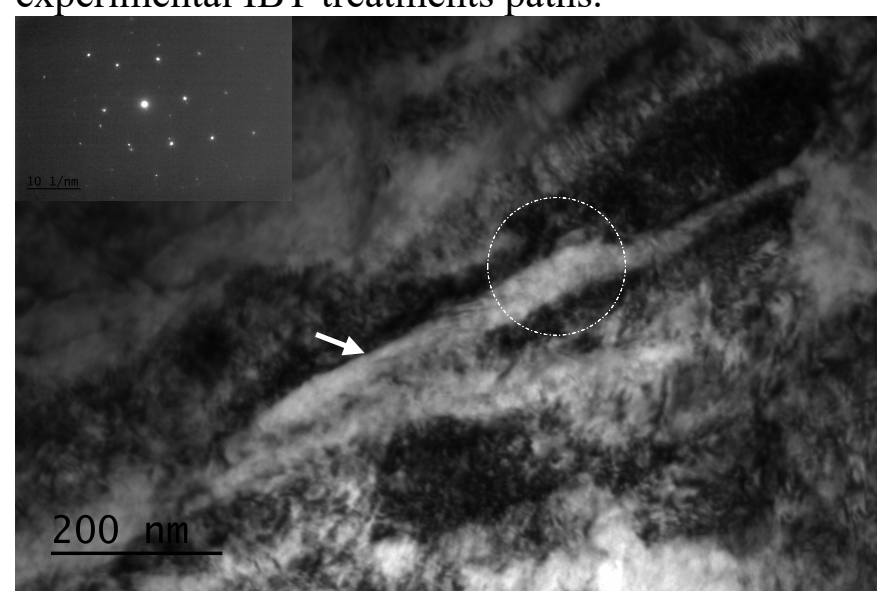

Figure 3. Bright Field TEM micrograph at $350^{\circ} \mathrm{C}-1800 \mathrm{~s}$ IBT, showing lamellar structure of interRA and bainitic ferrite.

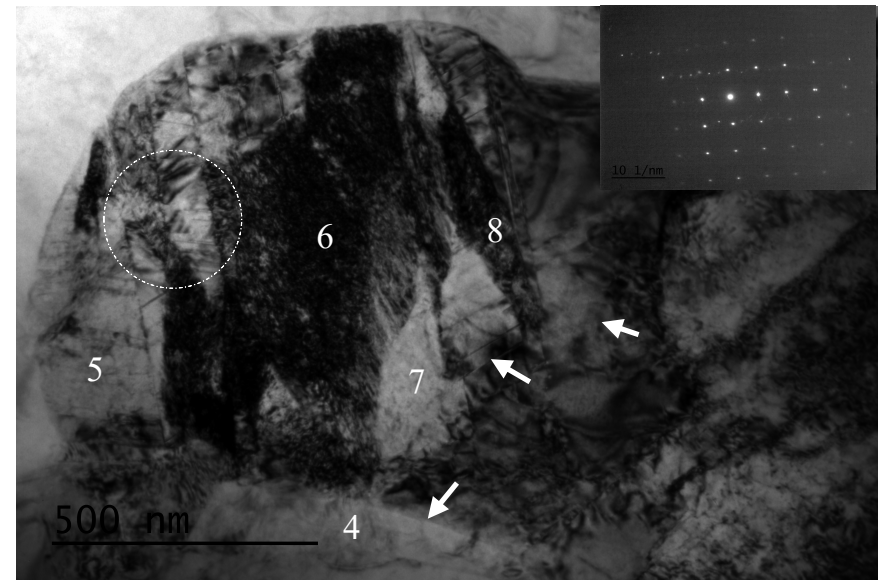

Figure 5. Bright Field TEM micrograph at $400^{\circ} \mathrm{C}-300 \mathrm{~s}$ IBT, showing lamellar structure of bainitic ferrite, InterRA and IntraRA (deformed).

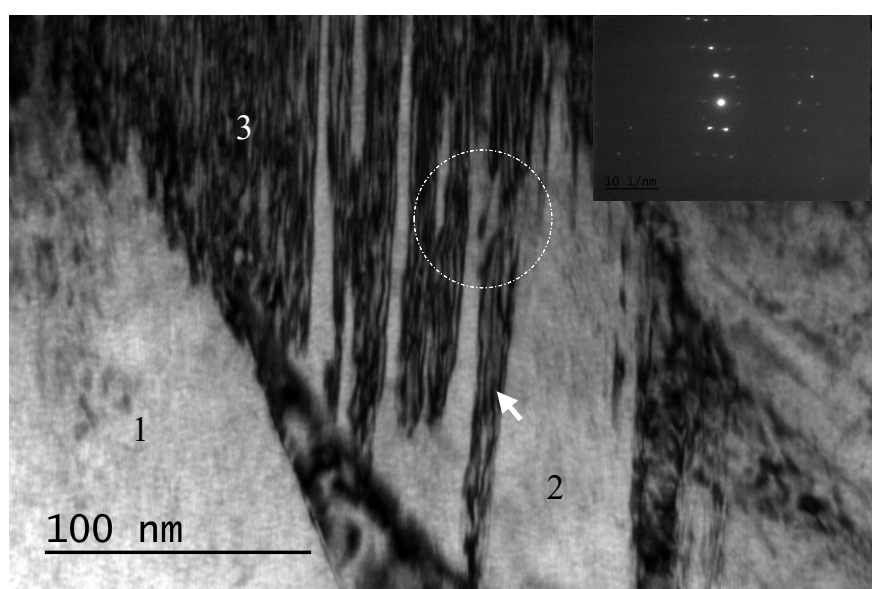

Figure 2. Bright Field TEM micrograph at $350^{\circ} \mathrm{C}$ 300s IBT, showing IntraRA / bainitic ferrite lamellar structure.

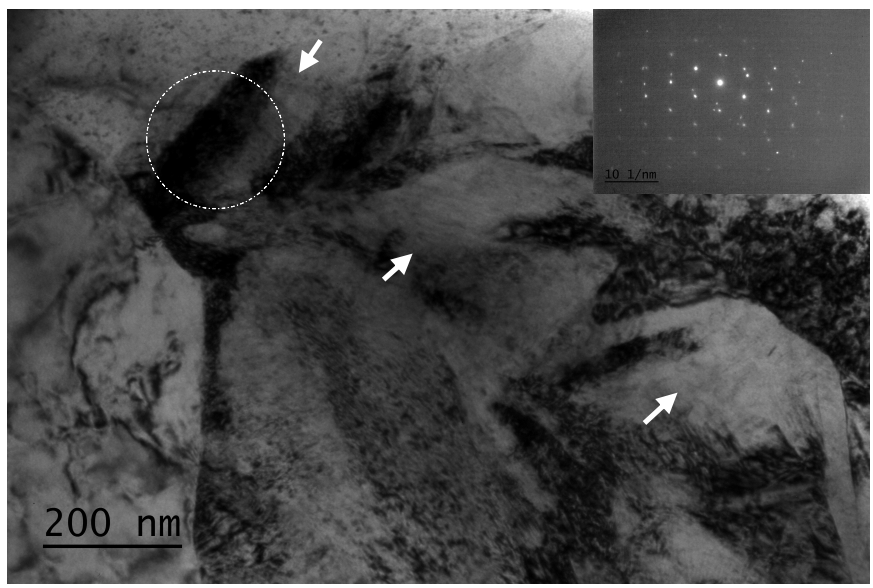

Figure 4. Bright Field TEM micrograph at $400^{\circ} \mathrm{C}$ 120 s IBT, showing twinned structure of retained austenite (deformed).

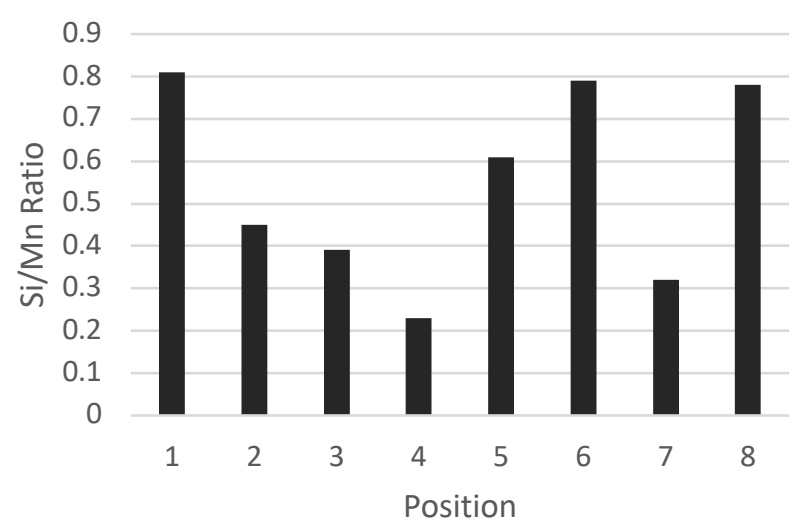

Figure 6. Si/Mn ratio of the corresponded positions obtained via STEM / EDX spot microanalysis. 